\title{
The Effect of Knowledge Management through Human Resources Information Systems on Customer Relationship Management in Aquatic Sport Centers
}

\author{
${ }^{1}$ Mohammad Keshtidar ${ }^{*}$, ${ }^{2}$ Mohamad Reza Esmaeilzade Ghandehari, ${ }^{2}$ Mohsen Harati \\ ${ }^{1}$ University of Birjand, Birjand, Iran. ${ }^{2}$ Mashhad Branch, Islamic Azad University, Mashhad, Iran.
}

\begin{abstract}
Objectives. The purpose of this research is to investigate the impact of knowledge management through information systems of human resources on customer relationship management. Methods. The study population included managers and employees of Mashhad's aquatic sport centres like 'Blue Waves', 'Armaghan', 'Surging Waves', and 'Sunshine Coast Park' (600 persons). Using a Morgan table, 234 cases were selected as sample, based on cluster sampling method, and randomly. The research method was descriptive-analytical. Data collection was conducted as a field study. The measurement tools were knowledge management questionnaire and human resources information systems questionnaire and customer relationship management questionnaire respectively. The validity of the questionnaires was observed andapproved by 10 sports management experts and professors of Azad University of Mashhad and Ferdowsi University of Mashhad.Validation was determined by Cronbach's alpha respectively as $0.91,0.87$ and 0.90 . Results. The results showed that knowledge management through human resources information systems has a significant positive effect on customer relationship management. Conclusion. It can be said that aquatic sport centers should more attend the important role of information systems to increase customer satisfaction along with knowledge management.
\end{abstract}

KEY WORDS: Knowledge Management, Human Resources Information Systems, Customer Relationship Management, Aquatic Sport Centers.

\section{INTRODUCTION}

The modern world is the world of knowledge-based organizations. In order to achieve new sources of knowledge, knowledge management relies on modern theories such as social knowledge management, which seeks access to a large volume of customers (1). In recent years, knowledge management is considered a key tool to improve efficiency and organizational performance (2) and organizations have been allowed to identify market opportunities and increase their competitive advantage (2).The current value and future success of any organization depends entirely on the capabilities and skills of its employees. Today, the employees are the main source of competitive advantage, not raw materials, capital or technology; organizations that have enabled people can make decisions quickly in global markets and keep pace with the speed of the networks (3). For decades, the

*. Corresponding Author:

Mohammad Keshtidar

E-mail: mkeshtidar@birjand.ac.ir 
development of information technology (IT) and knowledge management in creating competitive advantage has been one of the leading concerns of managers and scholars. Today's increasingly changing environment makes the emergence of IT-enabled knowledge management capability (KMC) as a core competency for organizations to enhance individual performance, innovation, organizational capabilities, and competitive advantage (4).

Knowledge management is the process of discovering, acquiring, developing, sharing, maintaining, evaluating and applying appropriate knowledge by the right person in the organization, which is conducted through linking human resources, information and communication technology (ICT) and providing an adequate infrastructure to achieve organizational goals (5). Knowledge management is a new way of managing the organization and of sharing intellectual and scientific resources (6). Knowledge management can be the creative, effective and efficient use of any form of knowledge in order to attract and retain customers and improve the organization; in other words, knowledge management is defined as the use of individual and collective knowledge of the employees to achieve organizational goals (7). Knowledge management creates a tool to institutionalize management of customer relationships. Knowledge management in organizations helps transparency in terms of fragmented geography, because it creates access to knowledge. Therefore, customer knowledge can be stored at a central point, and since it has been shared to form a common image of the customer, it increases the quality and speed of decisionmaking and customer service (8).

In today's world, competition has taken on a new shape and a continuous and long-term relationship with the customer is the most fundamental key to success in organizations (7). Organizations and companies are well aware that to survive in the competition, they should be able to acquire knowledge correctly and in a timely manner from the surrounding environment, especially customers who are the main cause of organizational life. This way, by timely understanding of the changes and requirements of customers, it goes towards effective interaction with the environment (9). In today's environment, technology and customer needs are constantly changing, so identifying customer needs and meeting them in the shortest possible time at the lowest cost and highest quality are very important and play a significant role in the success and survival of firms. New management approaches have been developed and used and, at the same time, appropriate information systems that can support these new approaches have developed over time to deal effectively with such situations (10).

The human resource information system (ERP) is a comprehensive system that tries to integrate all functions and departments within the organization, using a unit computer system, so that it can provide the specific and special needs of these sections. In other words, it is a thought, technology and systems for more effective management of resources in an organization, such that management is conducted by automating and integrating all processes, thereby enhancing the efficiency of the organization and increasing customer satisfaction (10). The advantages of implementing this system are to streamline the sustainable business processes, cost reductions, and quality improvements that lead to securing economic improvement, social equity and justice, and environmental protection (11).

Customer relationship management system - a business strategic system to create long-term and profitable relationships with our customers - can reduce transaction costs for the consumers or unknown costs, which, in turn, enhances the relationship between the customer and the company. Customer relationship management can also be effective for relationship quality and is considered an important factor in assessing the relationship between the company and the customer in strong or weak, good or bad perspectives $(12,13)$. In fact, customer relationship management is the enterprise behaviour that is a business strategy to increase loyalty and acquire higher profits by understanding and reaching customers through full engagement of the organization's efforts (14). The main purpose of customer relationship management is to maintain existing customers by increasing their loyalty and attracting new customers for greater profitability (15). 
Rezaei-Malek and Radfar (2013), providing a model for the prioritization of knowledge, stated that organizations that can categorize and implement the knowledge management from three different viewpoints - of customer knowledge, employee knowledge and market knowledge - create acceptable improvements in customer relationship management in their organizations (7). Knowledge management through knowledge resources has a positive and significant effect on different aspects of customer relationship management i.e. customer satisfaction, customer loyalty, customer acquisition and customer interaction. Accordingly, the highest effectiveness of knowledge management has been in relation to customer satisfaction and even loyalty, absorption and interaction with the customer on the next level (5). Jafari Navimipour and Soltani (2016) have concluded that infrastructure capability, ease of use, and E-learning systems, and the complementarily between these factors positively influences the effectiveness of the ECRM. The results of gathered data from 210 employees of the East Azerbaijan Tax Administration in Iran has indicated that the impact of the technology acceptance on organization performance begins with infrastructure capability, ease of use, and Elearning systems, and the complementarily between these factors positively influences the effectiveness of the E-CRM. The results have also indicated that the customer costs positively affects on the customer relationship performance, which consequently leads to improvements of the effectiveness of the E-CRM in organization (16). Our findings show that each of cost, technology acceptance and satisfaction employee plays an important role toward in effectiveness of the E-CRM.

It has conducted a literature review on the topic, by designing a questionnaire and providing it to 100 to 297 managers and experts, who comprised the study population. Based on the results obtained from statistical analysis, the effect of customer knowledge management on customer relationship management was confirmed (17). Besides, other study has concluded that more human factor has greater influence on the successful implementation of knowledge management in the bank's customer knowledge management (17). Jayasundara (2008), after studying knowledge management in the banking industry, emphasized that it is the banking or information-centred activities and creation of available information and knowledge, at the right time and without delay, as a vital necessity, and considered applications of knowledge management in the banking industry, including risk management, customer relationship management, evaluation, systems, decision support, data warehousing and data mining (18).

Salomann et al. (2005) discussed the main components of the customer knowledge management model like the strategies, processes, systems and management change with the theme of knowledge management capabilities in customer relationship management (19). The strategy is described in a way that the senior management should recognize that the knowledge received from the customer is a valuable resource for product or service innovation and process improvement. In the process, knowledge management activities should be aligned with customer relationship management processes. The systems are the creation of integrated knowledge source against the organizational constraints. Finally, senior management must change the organizational culture and encourage employees to share their knowledge about the customer and the customer's knowledge (17). It found that by integrating customer relationship management and knowledge management systems, its benefits can be increased and risk can be reduced (20).

In recent years, the company with the integration of its efforts came to the conclusion that knowledge management plays a key role in the success of customer relationship management. Relationships with customers should have a solid understanding of tacit knowledge exchange. Adequate and continuous updating of customer knowledge in customer relationship management is very important. Therefore, customer knowledge is a rare or valuable asset for the business, which provides the possibility to generate quick responses to 
customer needs and adapt to changing markets (21). Customer relationship management (CRM) is an important concept to maintain competitiveness at e-commerce (16). Over the last decade, both academics' and practitioners' research interest in the development and management of supplier-customer relationships has significantly increased (22). Since research on the effects of the mediating role of human resource information system interfaces with the knowledge management on customer relationship management is rarely conducted, therefore, in this study, the effect of knowledge through the mediating role of human resources information systems on customer relationship management will be discussed.

\section{MATERIALS AND METHODS}

Participants. The study population included managers and employees of Mashhad's aquatic sport centres, such as 'Blue Waves', 'Armaghan', 'Surging Waves', and 'Sunshine Coast Park' (600 persons). Using a Morgan table, 234 cases were selected as the sample, based on cluster sampling method, and randomly.

Tools. The measurement tools were three questionnaires. Knowledge management questionnaire of Newman and Conrad (2000), which contains 21 questions and four subscales (maintaining knowledge, knowledge transfer, knowledge creation and application of knowledge) and is measured based on a 5value Likert scale, such that the validity of 0.91 has been obtained by Cronbach's alpha in this study (23). An inventory of human resource information systems, which contains 22 questions and two subscales (advantages and potential barriers), and is based on a 5value Likert scale, has been measured, such that the validity of 0.87 was obtained by Cronbach's alpha. The customer relationship management inventory, which contains 29 questions and eight subscales (marketing research and analysis of needs, planning for customer friendliness, service quality, customer-focused strategic activities, management of customer complaints, satisfaction for customers, facilitation of the exchange of information and communication, skills and training of staff) and has been measured based on a 5-value Likert scale, such that the validity of 0.90 has been obtained by Cronbach's alpha in this study. In this research, to ensure more before getting Cronbach's alpha to confirm the validity, questionnaires were observed and approved by 10 experts and professors of sports management of Azad University of Mashhad.

Statistical Analysis. A Kolmogorov-Smirnov test and appropriate inferential statistics, such as confirmatory factor analysis and structural equation analysis, were used, deploying LISREL software analysis and-in some data-software SPSS in descriptive statistics.

\section{RESULTS}

Based on Kolmogorov-Smirnov test, given that all variables of this research are normally distributed.

Confirmatory factor analysis is done before path analysis. Whether the selected questions provide suitable operating structures to measure the dimensions studied in the research model is discussed (table 1).

As can be seen from the table 1, the t-value in all questions of different aspects is larger than 1.96. Also, the AVE values obtained for each variable are more than 0.5 ; hence, it can concluded that the selected questions provide appropriate operating structures for measuring variables and dimensions studied in the research model.

In the table 2, the fitness index values have been shown. The RMSEA value is equal to 0.056 and, considering the fact that it is less than 0.08 , the model is acceptable. The relative chi-square value i.e. the chi-square divided by the degree of freedom is equal to 1.59 (119.78 / 75) and between 1 and 3 and, indices AGFI, GFI, IFI, CFI and NFI are also more than 0.9. Overall, the indicators are consistent with the interpretational criteria, and the confirmatory factor analysis confirms the structure of dimensions examined in the study. 
Table 1. Results of confirmatory factor analysis of variables.

\begin{tabular}{clcc}
\hline \multicolumn{1}{c}{ Variables } & \multicolumn{1}{c}{ Dimensions } & $\begin{array}{c}\text { Factor } \\
\text { load }\end{array}$ & $\begin{array}{c}\text { T- } \\
\text { value }\end{array}$ \\
\hline Knowledge management & Preservation and maintenance of knowledge & 0.65 & 3.67 \\
Human Resources & Knowledge transfer & 0.74 & 7.97 \\
Information Systems & Knowledge creation & 0.54 & 2.10 \\
& Application of knowledge & 0.87 & 8.81 \\
\hline & Marketing research and analysis of needs. & 0.54 & 2.34 \\
& Planning for being customer-friendly & 0.49 & 2.09 \\
& Quality of service & 0.59 & 3.01 \\
Customer relationship & Strategic customer-focused activities & 0.52 & 2.31 \\
management & Customer complaints management & 0.61 & 3.37 \\
& Customer satisfaction & 0.73 & 3.87 \\
& Facilitation of the exchange of information and communication & 0.78 & 3.88 \\
& Skills and Training & 0.56 & 2.94 \\
\hline Human Resources & Advantages & 0.65 & 7.97 \\
Information Systems & Obstacles & 0.63 & 7.59 \\
\hline
\end{tabular}

Table 2. The fitness parameters of the model

\begin{tabular}{ccccccc}
\hline$\chi 2 / \mathrm{df}$ & RMSEA & NFI & CFI & IFI & GFI & AGFI \\
\hline 1.59 & 0.056 & 0.93 & 0.92 & 0.92 & 0.91 & 0.93 \\
\hline
\end{tabular}

Figures 1-a and 1-b respectively exhibit the diagrams of path coefficients and t-values of structural equation modeling to investigate the hypothesis. The summary of the results of the model has been given in the table 3 .

Investigation of the research hypothesis: knowledge management - through human resources information systems - has significant positive effect on customer relationship management.

This hypothesis investigates the mediating effect of the parameters of human resources information systems (mediator variable) on the relationship between the independent variable 'knowledge management' and dependent variable 'customer relationship management'. For investigation of the indirect effects of the independent variable on the dependent variable, the following conditions have to be established first. The first condition is that the significance of the relationship between independent and mediating variable is confirmed, and the second condition is also the confirmation of significance of the relationship between the dependent and mediating variable. Then, in the case of establishment of the above conditions, the path coefficient of indirect relationship is obtained by multiplying the path coefficient of the relationship between independent and mediating variable by path coefficient of the relationship between the mediating and dependent variables. These conditions are assessed in the following.

According to Table 3, path coefficient between knowledge management and human resources information systems is equal to the positive value of 0.71 . The t-value is equal to 7.71 , which is more than 1.96 ; so, with $95 \%$ confidence, it can be concluded that this path coefficient is significant at the level of errors of 0.05 and a significant and direct (positive) relationship between knowledge management and human resources information systems is confirmed. Also, the path coefficient between human resources information systems and customer relationships management is equal to the positive value of 0.66 . The $t$-value is equal to 2.09 , which is more than 1.96.So, with $95 \%$ confidence, it can be concluded that this path coefficient is significant at the level of errors of 0.05 and a significant and direct (positive) relationship between human resources information systems and customer relationships management is confirmed. Hence, the first and second conditions are established and the path 
coefficient of indirect relationship of knowledge management through mediator variable of human resources information systems of customer relationship management is calculated as follows.

$0.71 \times 0.66=0.46$
Hence, it can be said that knowledge management is confirmed through human resources information systems, having a significant and positive impact on customer relationship management, and so the research hypothesis is confirmed.

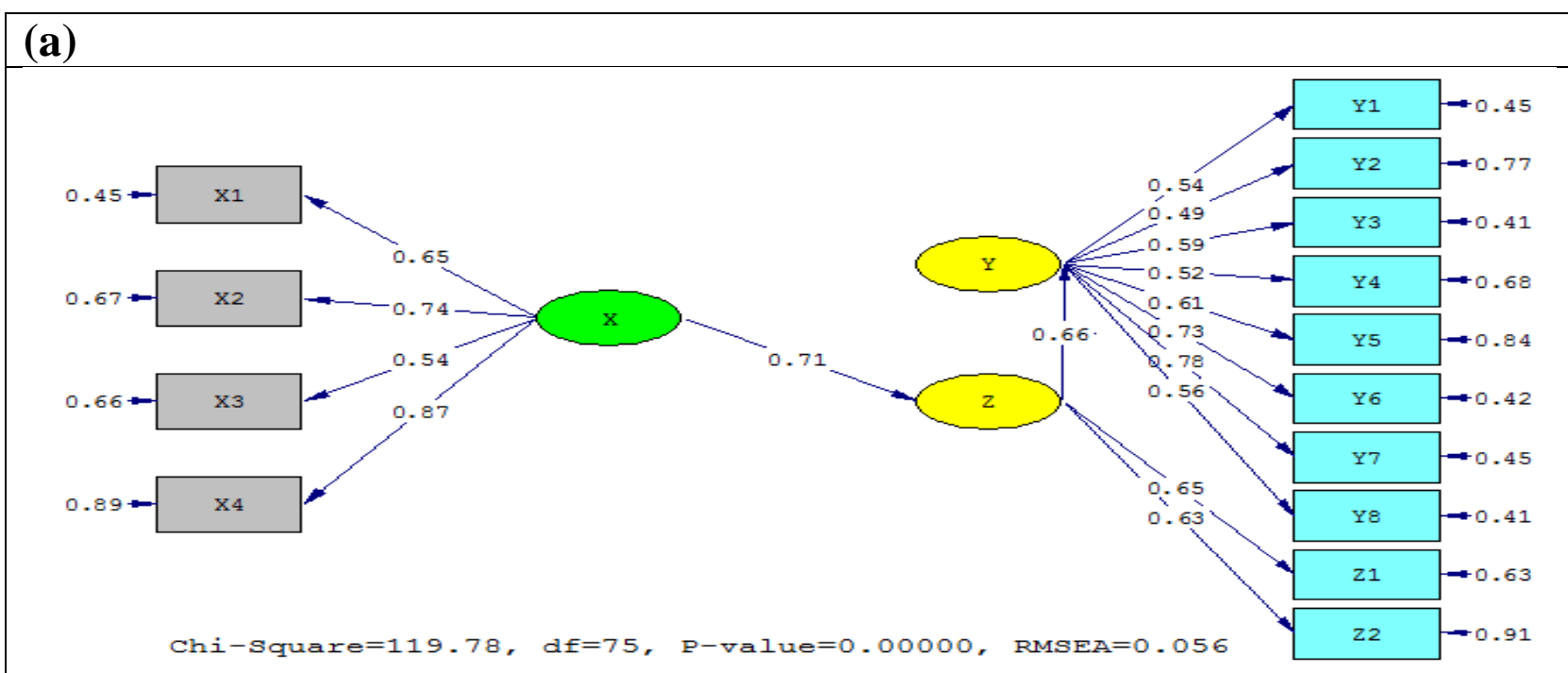

(b)

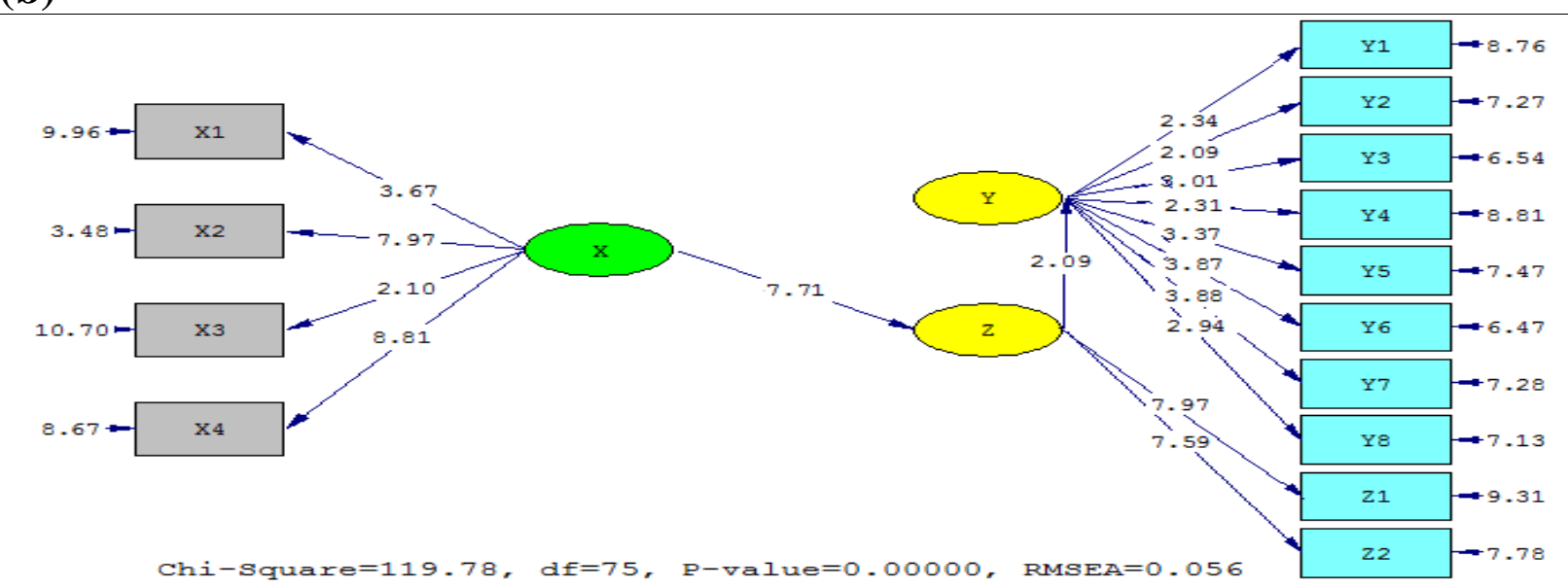

Figure 1. (a) Factor coefficients and path coefficient of the research model. (b) $t$ statistic values for the research model. x: Knowledge management (independent variable), y: the amount of customer-friendliness (the dependent variable), z: Human Resource Information Systems (mediator), x1: to preserve and maintain knowledge, x2: the knowledge transfer, x3: knowledge creation, x4: application of knowledge, y1: marketing research and analysis of needs, y2: planning to be customer-friendly, y3: quality of service, y4: have a strategic vision of being customerfocused activities, y5: customer complaints management, y6: satisfaction for customers, y7: easy transfer of information and communication, y8: skills and training, z1: Benefits, z2: Obstacles.

\section{DISCUSSION}

Basically, organizations employ human resources with various methods, but without the use of appropriate human resources information systems, customer-orientation cannot be properly identified and customer relationships cannot be managed well and improved. This paper has pointed out the 
importance of human resource information systems as the mediating role of knowledge management with customer relationship management and discusses its importance in aquatic sport centres. So, at first, the impact of knowledge management on information resources systems was analysed, and the results showed a positive and significant direct impact of knowledge management on human resource information systems ( $t$ value $=7.71$, path coefficient $=0.71$ ), which was the greatest impact on the component of knowledge application, because the ideas and viewpoints of managers' and employees' creativities to submit positive ideas are considered, such that this leads to rapid response and quick access to information and promotion of competitiveness and improved service to customers. In the dimension of creation of knowledge, it had the least impact, because problems, failures and doubts are openly expressed and people were selected considering the expertise and skills. Their availability and rewards were dedicated to them less for developing new knowledge and testing and for providing new ideas. Therefore, the creation of knowledge is of less concern. All of this is affected by factors, such as the lack of knowledge required to implement the system or inadequate financial support or concern of changing the way of doing things. Salomann et al. (2005) discusses the main components of the customer knowledge management model i.e. strategies, processes, systems and management change (19). Also Honari et al. (2015) concluded that in the field of information technology, the use of the internet and the management information system, the use of staff database has higher importance and priority for managers. Also, between IT and organizational performance, between management information systems and organizational performances, there is a significant positive relationship. And the variable of information technology, in comparison with management information system, is a stronger predictor to improve organizational performance in physical education (24).

Table 3. Results in order to test the research hypotheses

\begin{tabular}{lllccc}
\hline \multicolumn{2}{c}{ Relationships } & $\begin{array}{c}\text { Path } \\
\text { coefficient }\end{array}$ & $\begin{array}{c}\text { t- } \\
\text { value }\end{array}$ & Result \\
\hline Knowledge Management $\rightarrow$ Human Resources Information Systems & 0.71 & 7.71 & significant \\
\hline $\begin{array}{l}\text { Human Resources Information Systems } \rightarrow \text { Customer } \\
\text { Management }\end{array}$ & Relationship & 0.66 & 2.09 & significant \\
\hline $\begin{array}{l}\text { Knowledge Management } \rightarrow \text { Human } \\
\text { Customer Relationship Management }\end{array}$ & Resources Information Systems $\rightarrow$ & $\begin{array}{c}0.46=0.66 \times \\
0.71\end{array}$ & - & significant \\
\hline
\end{tabular}

The effects of human resources information systems on customer relationship management were then discussed: the findings showed that human resources information systems impact positively and significantly on customer relationship management. So, in terms of priorities of influence among the components of customer relationship management, the component of ease of information exchange had the greatest impact because human resources information systems lead to factors such as rapid response and quick access to information and improved data control, and make HR processes more efficient and reduces errors, aids standardization of programs and procedures, reduces manpower, helps monitor various human resources, and contributes to more informed decisions. These factors all lead to information exchange among customers of aquatic centres and create a secure communication channel for receiving customer feedback, resulting in the ease of communication even for outsiders. A customer-friendly planning component had the least impact because issues such as financial problems, lack of expertise in the field of information technology, lack of senior management commitment to the organization, insufficient commitment and 
employee involvement, the large volume of paperwork and the difficulties for computerization may lead to the fact that customer surveys conducted less and customers' needs and demands have not been collected regularly. Eventually, it caused less attention to planning for being customerfriendly Jafari Navimipour and Soltani (2016) in their study have concluded that infrastructure capability, ease of use, and Elearning systems, and the complementarily between these factors positively influences the effectiveness of the E-CRM. The results of gathered data from 210 employees of the East Azerbaijan Tax Administration in Iran has indicated that the impact of the technology acceptance on organization performance begins with infrastructure capability, ease of use, and E-learning systems, and the complementarily between these factors positively influences the effectiveness of the E-CRM (16). The results have also indicated that the customer costs positively affects on the customer relationship performance, which consequently leads to improvements of the effectiveness of the E-CRM in organization. Our findings show that each of cost, technology acceptance and satisfaction employee plays an important role toward in effectiveness of the E-CRM . a research on the subject of how customer knowledge management in Iranian banks could be implemented with a focus on human resources concluded that human factors has greater influence on the successful implementation of customer knowledge management in the bank (17).

\section{CONCLUSION}

Finally, considering the structural model obtained, it was determined that knowledge management through human resources information systems affects the customer relationship management. In this respect, one of the ways to make a profit in sport complexes can be giving Attention to the customer and the relationship with the customer.

\section{APPLICABLE REMARKS}

- The sport managers had better must pay attention to the importance of teamwork and the use of expert and experienced human resources that are considered as knowledge assets, or the source of knowledge of each organization.

- Sport managers, undoubtedly, in order to achieve a context of both customer satisfaction and profitability should be synchronized with the updated technology so that it would be possible to immediately identify the challenges of the complex and the needs of the customer and to compensate for the correct management of the facilities.

- Sport managers can achieve more efficiency if they consider the importance of using integrated systems and standards in the organization; because these systems will reduce direct costs of operations, accelerate response time, improve productivity, improve interaction with customers, improve product quality, improve order cycle management and customer data integration, increase time management planning and ensure better management of resources and the organization. In fact, sports executives have provided the foundation for growth in their own organization, which not only addresses the issue of overseeing a better organization, but also satisfaction of customers and employees, and turning that organization into a model of superiority.

\section{REFERENCES}

1. Mohseni F, Seyed Danesh SY, Chirani E. The study of knowledge management's effect on CRM success, considering the intermediary effect of organizational factors. International Journal of Economy, Management and Social Sciences. 2014;3(8):396-9. 
2. Zack M, McKeen J, Singh S. Knowledge management and organizational performance: an exploratory analysis. Journal of Knowledge Management. 2009;13(6):392-409.

3. Byrne J. The search for the young and gifted: why talent counts. Business Week. 19994 October:108-16.

4. Mao H, Liu S, Zhang J, Deng Z. Information technology resource, knowledge management capability, and competitive advantage: The moderating role of resource commitment. International Journal of Information Management. 2016;36(6, Part A):1062-74.

5. Salavati A, Cafcheh P, Salehpoor K. The Study of the Effects of Knowledge Management (KM) on Customer Relationship Management (CRM) in Refah Bank (case study: Kurdistan Province). Quarterly Journal of Productivity Management. 2011;5(16):59-78 [Article in Farsi].

6. Vaezi R, Moslemi T. The Identification of Effective Organizational Factors Influencing the Implementation of Knowledge Management System: The Case Study of Hamkaran System Company. Journal of Development \& Evolution Mnagement. 2009;1(1):7-19 [Article in Farsi].

7. Rezaei-Malek N, Radfar R. Providing a Model for Setting Priorities in KM for Improving Customer Relationship Management (Case study: Sepah Bank). Journal of Information Technology Management. 2013;5(3):63-82 [Article in Farsi].

8. Plessis Md, Boon JA. Knowledge management in eBusiness and customer relationship management: South African case study findings. International Journal of Information Management. 2004;24(1):73-86.

9. Gholamy Avati R, Ebrahimiyan Jelodar SY. The Study of Customer Knowledge Management Effec on Customer Relation Management. Police Organizational Development. 2013;9(4):65-81 [Article in Farsi].

10. Faghri J, Karimi M, Heidari S. Enterprise Resource Planning and Transformation in Hospital Management. Health Information Management. 2006;3(2):113-23 [Article in Farsi].

11. Gholamzadeh Chofreh A, Goni FA, Ismail S, Mohamed Shaharoun A, Klemeš JJ, Zeinalnezhad M. A master plan for the implementation of sustainable enterprise resource planning systems (part I): concept and methodology. Journal of Cleaner Production. 2016;136(Part B):176-82.

12. Crosby LA, Evans KR, Cowles D. Relationship Quality in Services Selling: An Interpersonal Influence Perspective. Journal of Marketing. 1990;54(3):68-81.

13. Storbacka K, Strandvik T, Grönroos C. Managing Customer Relationships for Profit: The Dynamics of Relationship Quality. International Journal of Service Industry Management. 1994;5(5):21-38.

14. Wu S-I, Li P-C. The relationships between CRM, RQ, and CLV based on different hotel preferences. International Journal of Hospitality Management. 2011;30(2):262-71.

15. Karahan M, Kuzu ÖH. Evaluating of CRM in Banking Sector: A Case Study on Employees of Banks in Konya. Procedia - Social and Behavioral Sciences. 2014;109:6-10.

16. Jafari Navimipour N, Soltani Z. The impact of cost, technology acceptance and employees' satisfaction on the effectiveness of the electronic customer relationship management systems. Computers in Human Behavior. 2016;55(Part B):1052-66.

17. Teimourpour B, Amiri Aghtaee R. Using interpretive structural modeling (ISM) to develop a customer knowledge management model in banking industry. Organizational Resources Management Researchs. 2015;4(3):1-22 [Article in Farsi].

18. Jayasundara CC. Knowledge Management in Banking Industries: uses and opportunities. Journal of the University Librarians Association of Sri Lanka. 2008;12:68-84.

19. Salomann H, Dous M, Kolbe L, Brenner W. Rejuvenating Customer Management:: How to Make Knowledge For, From and About Customers Work. European Management Journal. 2005;23(4):392-403.

20. Gibbert M, Leibold M, Probst G. Five Styles of Customer Knowledge Management, and How Smart Companies Use Them To Create Value. European Management Journal. 2002;20(5):459-69.

21. Garrido-Moreno A, Padilla-Meléndez A. Analyzing the impact of knowledge management on CRM success: The mediating effects of organizational factors. International Journal of Information Management. 2011;31(5):43744.

22. Paraskevi D, Panagiotis T. Organizational structure, innovation performance and customer relationship value in the Greek advertising and media industry. Journal of Business \& Industrial Marketing. 2017;32(3):385-97.

23. Newman BD, Conrad KW, editors. A Framework for Characterizing Knowledge Management Methods, Practices, and Technologies. Third Int Conf on Practical Aspects of Knowledge Management (PAKM2000); 2000 30-31 Oct 2000; Basel, Switzerland.

24. Honari H, Mahmoudi A, Eslami A, Mottaghi Shahri MH. The relationship between IT and MIS With Organizational Performance in Physical Education Managers of the Education System. Organizational Behavior Management in Sport Studies. 2015;2(7):89-102 [Article in Farsi]. 